\title{
A PRELIMINARY ANALYSIS \\ OF THE RESULTS IN \\ THE PROJECT 'TYPOLOGIES \\ OF UNDERDEVELOPMENT \\ AND MARGINALIZATION IN RURAL \\ LOCALITIES AND SMALL TOWNS \\ IN ROMANIA'1
}

\author{
Mihnea PREOTESI ${ }^{2}$ \\ Cristina TOMESCU ${ }^{3}$ \\ DOI: $10.35782 /$ JCPP.2020.3.01
}

\begin{abstract}
The project begins from the coordinates provided by the sociological literature which show that local underdevelopment is the result of structural factors as lack of employment and the predominance of employment in (subsistence) agriculture, lack of infrastructure (access to public utilities such as gas, drinking water or paved roads) but also the distance to the nearest city that could be a pole of development or human capital (the education stock of the local population) and it tries to refine the analysis by overlapping the typology looking at local contexts and by deciphering the factors and mechanisms of underdevelopment at local level. The proposed approach has an
\end{abstract}

\footnotetext{
${ }^{1}$ Articol realizat în cadrul Grantului de cercetare Nr. GAR-UM-2019-XI-5.6-7/ 15.10.2019, cu denumirea Tipologii ale subdezvoltării şi marginalizării în localităţile rurale şi oraşele mici din România (MARGINALRURAL), grant realizat cu sprijin financiar din Fondul Recurent al Donatorilor, aflat la dispoziţia Academiei Române şi gestionat prin Fundaţia „PATRIMONIU” GAR-UM-2019

(Article within the Research Grant No. GAR-UM-2019-XI-5.6-7/15.10.2019, with the name Typologies of underdevelopment and marginalization in rural localities and small towns in Romania (MARGINALRURAL), grant with financial support from the Recurrent Donor Fund, available to the Academy Romanian and managed by the "PATRIMONIU" Foundation GAR-UM-2019)

2 Senior Researcher, The Research Institute for Quality of Life, Romanian Academy; E-mail: mihneapre1@yahoo.com

3 Senior Researcher, The Research Institute for Quality of Life, Romanian Academy; E-mail: crisdobos@yahoo.com
} 
exploratory character. The article explain this approach in the first part, and in the second part presents a synthesis of the results of the analysis of the data collected in Alba county (as an exploratory case study) for testing the research tools in the first phase of the project.

Keywords: development, underdevelopment, marginalization, rural localities, small towns

\section{Introduction}

The project Typologies of underdevelopment and marginalization in rural localities and small towns in Romania is part of the strategic vision of the Romanian Academy, regarding the support of multi-disciplinary research on major topics for Romanian society. From this point of view, the proposed analysis involves various capabilities of the researchers, at the border between social, economic and psycho-social: employment, education and health services at the local level, local poverty rate, development or local underdevelopment, social exclusion/marginalization, social activism, etc. Another dimension of the Academy's strategy that is considered by the project refers to strengthening the research capacity of institutes by supporting researchers to carry out projects on topics relevant to Romanian society and their active involvement in describing and explaining social phenomena and processes.

In today's Romania, there are significant inequalities in economic development, as well as in social development between rural and urban areas, between large and small towns, between development regions, between the country's counties. On the other hand, in addition to these differences between the mentioned categories, there are also intracategory inequalities, between the counties of each region and between the localities of the same county.

In addition to the structural factors of development, certain characteristics that describe the local context enhance the development at the local level, both in terms of dynamics and development model and the impact on certain categories of population. Vulnerabilities and vulnerable people also exist in poor localities from poor areas, in underdeveloped localities from relatively developed areas, but also in localities with medium or high degree of development, either vulnerable in marginalized areas or marginal in non-marginalized areas.

Starting from the structural factors of development and from the typologies built on them and operationalized in social measurement models - such as the one proposed by Dumitru Sandu and operationalized in an index of local development - the added value of the proposed project lies in refining the analysis by overlapping this typology over a typology of local contexts and by deciphering the factors and mechanisms of 
underdevelopment, at local level. The proposed research has an exploratory character. In this research framework, we did not aim to test and validate some hypotheses, the approach being predominantly qualitative, but to substantiate some hypotheses to be tested and validated in future research.

The reduction of the initial budget, on the one hand and the unforeseen difficulties arising from the emergence and development of the COVID 19 pandemic, on the other hand, led to the need to reduce the volume of data collection within the project, without affecting the logic and objectives of the proposed approach. A condition in this sense was the maintenance of the representation of all categories of localities and counties selected according to the cross-criteria according to the model of the preliminary proposed typology in the design of this research. We also aimed at the balanced representation of each type of locality, at the level of each of the two selected development regions. Therefore, even if in some counties we selected only rural localities and in others we included small or very small towns, at the level of each of the two development regions, there are represented all four categories of proposed localities.

\section{Theoretical and conceptual framework}

The paradigm of social development is the result of the crossing of two types of approaches to the underdevelopment phenomenon, which are based on two competing theories: the theories of modernization, respectively the theories of dependence.

Modernization theories propose the paradigm of development as modernization, after an evolutionary scheme. According to this scheme, societies progress from the traditional to the modern stage, which represents the phase of their maturity. Beyond differences of perspective on modernization factors and their mode of action, "modernization theories converge on a common conclusion: underdevelopment is the common feature of the societies at an early or intermediate point on the road to modernity, in contrast to developed societies, which have reached this point "(Preotesi M., 2007, p.565).

One of the important models of economic growth in the economic literature is the model of W W. Rostow (1959), who talks about six stages of growth of societies: 1.) The traditional society, characterized by subsistence agriculture and a primary economy, in addition, a reduced capacity for economic growth due to reduced modern technologies. Also, it is characterized by reduced individual economic mobility and resistance to change. 2). The preconditions to take-off are represented by the external increase in demand of raw materials, large-scale investments (canals, ports irrigation), increased spread of technology, commercial agriculture develops, crops are exported, social structure changes, individual social mobility begins and the also development of national identity and common economic interests appear. 3). In the take-off phase, urbanization increases, industrialization takes place, technological discoveries occur. 
The 'secondary' sector (commodity producer) expands and the ratio between the secondary and primary sectors of the economy is moving towards the secondary. 4). The road to maturity leads to the diversification of the industrial base, more industries are expanding, and new ones are taking root. Transport infrastructure is developing. Largescale investments are made in social infrastructure, hospitals schools. 5). The period of mass consumption is represented by the industrial base that dominates the economy; the primary sector has a very low share in the economy and society consumes goods, consumers have disposable income, beyond basic needs for additional goods. Society is urbanizing, with a movement from rural to urban 6). In the post-consumer society (beyond consumption), people feel in a society with high economic security and are moving towards nonmaterial goods.

Sociological perspectives on modernization introduce social and cultural factors along economic factors. Such perspectives have Inglehart R. (1977), Voicu (2002), Emery and Flora (2006). Inglehart (1977) talks about a development model that is based on the cultural dimension and which has two axes: secular-rational values versus traditional values and values of self-expression versus survival values.

According to Emery and Flora (Emery \& Flora, 2006, p. 20) there are 7 types of capital that contribute to the transformation of communities: 1) natural capital, which refers to the particularity of the location, natural resources, geographical isolation, or nonisolation; 2) cultural capital: traditions, values, ways of relating to the world that determine certain types of action; this capital influences, the locally recognized power relations of some groups, determines certain types of local privileges; 3) human capital refers to people's skills and abilities to use local resources and access external resources and the ability of leaders to promote participation and inclusion, to act proactively in shaping the future of the community; 4) social capital refers to the cohesion of the community, it reflects the connection of people and organizations to do things together. A special type of social capital is the entrepreneurial social capital that influences the economic development of the community. The latter includes internal and external networks and local mobilization of resources; 5) political capital reflects access to power, organizations, parties, connection to resources, the ability of people to get involved in actions that contribute to the well-being of the community; 6) financial capital refers to the financial resources available to invest in the community, in business development, to support social and civic entrepreneurship, to accumulate well-being for community development; 7) built-up capital refers to infrastructure, to access resources and support activities.

Emery and Flora talk about a spiraling down in which case there is the decline of all types of capital: job loss, population decline, aging of the community, reduced fertility, young people leaving the community, income decline, loss of welfare transfer between 
generations, the decline of infrastructure, the decline of social capital. Deterioration of the quality of life in the community takes place through a system effect.

Spiraling up refers to increasing opportunities and community well-being: expanding human capital by accumulating knowledge and skills, increasing opportunities for young people to stay in the community, involving young people in entrepreneurship, investing in infrastructure, protecting the environment, increasing social capital, involvement in volunteering and philanthropy. The 7 types of capital interact with each other systemically, support each other in the situation of growth but also influence the case of decline. The perspective is therefore a functionalist one, the community is seen as a system in which any segment is related to another. Due to this interdependence, the change in one point of the system causes effects in the whole system.

Starting from A.G. Franck's (1996) theory of dependence, according to which exportoriented development solutions create harmful imbalances for poor communities, the model emphasizing the relationship of export of solutions from developed countries to underdeveloped countries, there were derived concepts such as regional development, in the sense of dependence on the large urban centers for the small localities around them.

One direction of analysis is the studies on the impact of structural development factors and how they are regulated by the functioning of local social mechanisms. In Romania, authors such as Cătălin Zamfir (2007), Sandu D. (1999, 2011) Voicu M. (2004), Voicu B. (2005), Tesliuc, Grigoraș, Stănculescu (2016), Preotesi M. (2013) designed models for analyzing the social development of communities in Romania.

The sociological perspective on modernization introduces as determinants of modernization, along the economic ones, the social and cultural factors. Newer approaches to the phenomenon of underdevelopment, give an increased importance, both to the stock of social capital and to that of human capital, on the one hand, as indicators, on the other hand, as predictors of social development. Community development is a particular case of social development. The model for measuring local / community development proposed by Dumitru Sandu (1999, 2011) identifies two types of structural factors of community development: human capital, respectively, infrastructure, at community level.

To measure local / community development, Sandu D. builds the local social development index to reproduce the current configuration of social development disparities in Romania. The local social development index is calculated by aggregating seven primary indicators. The relevant and available indicators for the community capital of the localities are (Sandu, 2011, p. 5) human capital (education stock at community level), vital capital (average age of people over 14 years and life expectancy at birth), material capital (number of cars per 1000 inhabitants, average area per dwelling, gas consumption per capita) and size, residence category of the locality. The 
conclusions of the 2011 Sandu's analysis show that life chances are strongly differentiated in Romania depending on where you live, and disparities are structured on four axes: urban-rural housing, residential concentration, access to services and infrastructure and employment sector, a fifth axis with limited relevance in urban space refers to relational capital, associated with cultural diversity.

These axes together with four fields: education, health, consumption, social relations constitute the framework of inequality of social development manifested at regional level. Sandu shows that the biggest axis of differentiation is between urban and rural. In Romania, the rural continues to have a much higher infant mortality than the urban, a lower life expectancy than the urban. The quality of housing is systematically better in urban than in rural areas for all counties in the country. A second axis refers to the chances of accessibility. Sandu shows that social development is higher in communes close to the city and in communities with access to European roads, compared to those that have access only to communal or county roads. Commuting is also a factor. Rural localities with increased commuting bring income within the community. The third axis refers to the predominant agricultural occupation of the population. In the plain communities the activities of growing cereals are predominant, associated with low incomes. Communities where animal breeding is a developed sector tend to be more socially developed. The fourth axis is given by the size of the locality as the number of inhabitants. In communes with a small number of inhabitants, mortality rates by age group tend to be higher. The fifth dimension is given by relational capital. Regarding the education stock, the average number of school years completed by the population in a locality is a relevant indicator for both urban and rural areas. (Sandu, 2011, p. 18-20).

\subsection{The perspective of marginalized areas}

In recent years, several studies dedicated to community development and the identification of marginal areas under World Bank funding in Romania (2015-2017) made typologies of marginalization, of disadvantaged urban and rural areas in Romania. Tesliuc, Grigoras, Stanculescu in The Atlas of Marginalized Rural Areas (2016) talk about rural poor communities, segregated communities, and marginalized rural communities. According to their analysis, most people at risk of poverty or social exclusion live in rural areas, but rural poverty comes in various forms, from poverty in small villages or with an aged population to communities with low human capital, low formal employment, improper housing.

The study shows that most analyzes of marginalization in Romania focused on rural areas at the level of the administrative unit (usually at the commune level) and only a few studies conducted at the level of locality, most based on qualitative research techniques. Most analyzes in Romania took into account the following indicators: human capital (education, health and the number of family members or children); employment (relative to the number of unemployed, undeclared work, work in 
subsistence agriculture); living conditions (quality of housing and connection to public utility networks). (p. 19-20).

The Atlas of Marginalized Rural Areas uses the term "marginalized rural areas" for compact urban areas inhabited by people with a disproportionately low human capital, few declared jobs and improper living conditions compared to residents in other rural areas. The following criteria are used as for marginalization: human capital - proportion of the population aged 15-64 who have graduated at most 8 classes, proportion of people with disabilities, chronic diseases or other medical conditions that hinder their daily activities, proportion of children ( $0-17$ years) of the total population; employment - proportion of people aged 15-64 who are not employed in the formal labor market (employees or employers) and do not follow a form of education, proportion of people aged 15-64 who are not employed in the formal labor market ( employees or employers) and do not follow any form of education; housing proportion of dwellings without electricity, proportion of overcrowded dwellings, proportion of dwellings without running water, housing insecurity (proportion of nonowner dwellings). (p 21). Also they look at the history of the area, access to public services, issues related to crime and public order, community relations, utilities (water, sewerage, electricity) geographical environmental barriers, environmental risks, key groups in the area and population fluctuations, major community problems interventions already implemented in the area.

On the other hand, The Atlas of Marginalized Urban Areas in Romania (World Bank, 2014) defines the different types of disadvantaged urban areas, as well as the "bags" of urban marginalization, where deprivation is the most severe. "Marginalized" urban areas are defined as areas within cities and municipalities that do not meet an appropriate standard on any of the three criteria, have a shortage of human capital, have a low level of formal employment and offer unsuitable living conditions. "Disadvantaged" urban areas are, by definition, areas within cities and municipalities that do not meet an appropriate standard on one or two of the above criteria. (p.4). Subtypes of marginalized urban communities are ghetto-type areas with poor quality blocks or in former working-class settlements, slum-type areas with makeshift houses and / or shelters, historic (central) areas of some cities (p.11).

In our research approach we propose, we aim to build an explanatory model of how contextual factors can enhance the action of structural factors of development. The experience of a series of previous projects in which some team members were involved (such as those summarized in Preotesi, 2014) reveals the importance of these contextual factors in shaping a local development model.

A first category of factors concerns the recent history of the locality and of the nearest important city from the perspective of the deindustrialization and reagrarization processes. A second category of factors concerns the ways of responding to the social 
change of the inhabitants of these localities - either passive ways, such as accessing social benefits, or active ways, such as professional reorientation, or ways of withdrawal, such as migration. We propose an in-depth analysis of the mechanisms and factors that shape the architecture of these choices at the individual-family level.

The Atlas of Marginalized Rural Areas (Stănculescu et al. 2016) reveals that regional differences are significantly larger in the case of marginalized rural communities, and the share of marginalized rural areas with a significant Roma population is important, except for the North East region, where the share of non-Roma communities is significantly higher compared to mixed or high share of Roma (over 20\%). According to this Atlas, in rural localities in Romania the proportion of the population aged 15-64 who graduated at most 8 classes is $47 \%$ (in marginalized rural areas, reaching $80 \%$ ). The proportion of people aged 15-64 who do never have attended a form of education and have never been employed on formal labor market (employees, employers or retirees) is of $54 \%$ in rural areas, respectively $83 \%$ in marginalized rural areas.(p.25, p.35)

According to the Atlas of marginalized urban areas mentioned (World Bank, 2014), marginalized areas are found in all types of cities, whether small, medium or large and in all regions of the country, but the share of these areas is over 10 times higher in Romanian very small towns compared to the very large ones. The proportion of the population living in advantaged areas, either in terms of human capital, housing or employment, is increasing, in direct proportion to the size of cities - from $29 \%$ in very small towns to $43 \%$ in small towns, $70 \%$ in medium-sized ones, reaching $79 \%$ in the big cities, respectively, $81 \%$ in Bucharest. At the regional level, the proportion of the population living in advantaged areas varies between $60 \%$ in the cities of the NorthEast and $79 \%$ in the Bucharest-Ilfov region. The share of the population in marginalized areas is $4.3 \%$ in the North-East and Center, $4.2 \%$ in the South-East and $3.7 \%$ in the West, while the other regions have equal rates or lower than the national average of $3.2 \%$.

According to an analysis of the answers to the open questions regarding the main local level problems identified by local institutional representatives, from data collected in 2017 in an MLSJ project, named SIPOCA code $4^{4}$, there are poverty and lack of jobs. The lack of jobs is compensated by the practice of subsistence and semi-subsistence agriculture and occasional activities, these types of precarious employment generating in work poverty. Employment in subsistence and semi-subsistence agriculture has a significant share of the total employed population according to NIS TEMPO data ${ }^{5}$, in

\footnotetext{
${ }^{4}$ Implementation of a public policy development system in the field of social inclusion at the level of Ministry of Labor and Social Justice", SIPOCA 4 code -2016-2018. The authors of this article were part of the projects as experts.

${ }^{5}$ National Institute of Statistics: http://statistici.insse.ro:8077/tempo-online/\#/pages/tables/insse-table
} 
the third quarter of 2019, over 2 million people were employed, cumulatively, in selfemployed activities in agriculture and as unpaid family workers.

At community level, precarious employment and low education stocks lead to poverty and social underdevelopment. The relationship between poverty, marginalization and local development is a complex one. Although there are certain areas of overlap, the maps of marginalized areas do not overlap with those of poverty (according to the cited sources). In addition, data such as those presented above show that the very benchmark to which marginalization refers is an indicator of the underdevelopment of the rural environment.

Poverty maps do not perfectly overlap with those of in-work poverty. The analysis of the results of the SIPOCA 4 project (MLSJ, 2016-2018) ${ }^{6}$, reveals that the relative poverty rate correlates positively with that of labor poverty and negatively correlates with the share of the employed population in the working age population. While the positive correlation between relative poverty and in work poverty is enhanced by the quality of employment, the negative correlation between relative poverty and the employment rate of the working age population is enhanced by the quantitative aspects of employment.

If both indicators have values significantly above the national average, the share of the employed working age population is relatively high, but a large share of the employed population is involved in activities that do not bring well-being.

When employment is effective, but a small share of the working age population is employed, the poverty rate is high, while that of working poverty is low. The ideal situation, in which both the poverty rate and the poverty rate at work are at a level significantly below the national average is conditioned by the existence of a large share of the employed working age population, and by the efficiency of employment. The simultaneous fulfillment of the two conditions is a premise of social development, but social development also depends on the type of employment, not only on its efficiency. Only in certain contexts is individual employment efficiency transferred to the high level of local development. ${ }^{7}$

The profile of marginalization is different in the case of Roma communities compared to non-Roma. While most marginalized rural areas are small, Roma communities tend

\footnotetext{
${ }^{6}$ Synthesized in Preotesi M., 2018

${ }^{7}$ This complex relationship between employment and social development will be the background of an analysis Preotesi Mihnea, (2020) chapter Analysis of the differentiated impact of the dynamics of individual well-being on the local development in the Romanian countryside. An analysis in the mountainous and submontane rural areas, in the volume Zamfir C., Stănescu I. (2020) Romania 19892019: social policies and strategic options, ongoing manuscript
} 
to be more extensive. A hare of $86 \%$ of Roma living in marginalized communities live in Roma communities with more than 250 inhabitants

Landform is one of the factors influencing rural marginalization. And according to this criterion, there are differences between the profiles of marginalized Roma communities and respectively non-Roma. While in the villages located in the plain the probability of having a marginalized area is three times higher than in mountain villages and hilly mountain villages, in general, Roma communities are much more numerous in marginalized rural areas in mountain villages and in hilly mountain villages.

Most communes with marginalized areas are medium-developed or poor, in terms of the share of the population that is at risk of relative poverty - the probability of having a marginalized area is almost 10 times higher in poor communes than in developed ones. In the case of marginalized Roma communities, they are significantly more likely to be in developed communities (with low poverty rates). In the case of Roma marginalized communities, they are significantly more likely to be located in developed communities (with low poverty rates), marginalization being associated, rather with the Roma ethnicity than with elements that characterize the local and zonal socio-economic context.

\section{Research methodology}

Starting from a social measurement models such as the one proposed by Dumitru Sandu and operationalized in an index of local development, our project refines the analysis referring to a typology of local contexts and by deciphering the factors and mechanisms of underdevelopment, at local level, through a qualitative methodology. The proposed research has an exploratory character.

The methodological approach was subsumed to the theoretical model that integrates the two complementary perspectives: the perspective of social (under) development and the perspective of social marginalization. By operationalizing the concepts into measurable indicators and crossing the two categories of indicators of underdevelopment, at local level, respectively, of the incidence of marginalized areas, we identified a list of indicators that characterize in various combinations, types of localities. Using these indicators as selection criteria, in a first phase, we selected several counties that integrate a significant number of such combinations of local factors of underdevelopment and marginalization.

The desk research and secondary data analysis stages resulted in the selection of counties, respectively, in the subsequent phase, the selection of localities where data are to be collected in the next stage of the project (in 2021). For the "piloting" of the proposed typology model, six counties were selected, according to the following algorithm: 1). we excluded the most developed, respectively, the most underdeveloped 2 
regions (North East, West Oltenia, West and Bucharest Ilfov); 2). from the remaining four development regions, we chose a region with a higher degree of development (Center region), respectively, one with a lower degree of development (South Muntenia Region); 3). in order to ensure the most complete representation of the typology of rural localities, in each of the two selected regions we also selected more developed counties and counties with a lower degree of development, in a regional context; we crossed this criterion with that of the degree of urbanization at county level and with that of intra-county development disparities. We also aimed to cover all types of landform combinations.

Table 1. Selection of development regions and counties and criteria used for selection

\begin{tabular}{|c|c|c|}
\hline $\begin{array}{l}\text { Development } \\
\text { region }\end{array}$ & $\begin{array}{l}\text { Selected } \\
\text { county }\end{array}$ & Selection criterion / county profile \\
\hline Center & Brasov & $\begin{array}{l}\text { County with varied landform, high degree of urbanization, } \\
\text { low rate of urban poverty and relatively high rate of rural } \\
\text { poverty - high share of Roma }\end{array}$ \\
\hline Center & Alba & $\begin{array}{l}\text { County with predominantly mountainous landform, with } \\
\text { medium degree of urbanization, with small and isolated } \\
\text { villages and with a large share of small towns, under } 10,000 \\
\text { inhabitants }\end{array}$ \\
\hline Center & Mureş & $\begin{array}{l}\text { County with varied landform, medium degree of } \\
\text { urbanization, high share of Roma and high rate of rural } \\
\text { poverty }\end{array}$ \\
\hline Sud Muntenia & Călăraşi & $\begin{array}{l}\text { County with plain landform, poorly urbanized, with a } \\
\text { pronounced agricultural profile }\end{array}$ \\
\hline South Muntenia & Argeş & $\begin{array}{l}\text { County with varied landform, relatively economically } \\
\text { developed, with low degree of urbanization and large intra- } \\
\text { territorial discrepancies }\end{array}$ \\
\hline South Muntenia & Dâmboviţa & $\begin{array}{l}\text { County with varied landform, relatively economically } \\
\text { developed, with a very low degree of urbanization and with } \\
\text { large intra-territorial discrepancies }\end{array}$ \\
\hline
\end{tabular}

The design of the research methodology focused on each of the project phases. If in the first phase we used an algorithm for selecting the counties, the second phase involved the elaboration of a methodology for selecting the localities in each of the 6 selected counties (Alba, Brașov, Mureș, from the Center region, respectively, Arges, Călărasi, Dâmbovița, in the South Muntenia region).

In substantiating the proposal of the project we made a preliminary analysis of the results of a previous project (in which data were collected for each locality in Romania) 
SIPOCA 4 (MLSJ / NIER, 2016-2018) from the perspective of the relevance of the locality size indicator as the main predictor of socio-economic development at local level. According to this criterion, we selected for the preliminary analysis rural localities and cities with a population under 20,000 inhabitants from the 6 selected counties. Rural localities were grouped into the following categories:

- rural localities with a population of less than 3000 inhabitants.

- rural localities with a population between 3001-6000 inhabitants

- rural localities with a population of over 6000 inhabitants

Therefore, the second phase of the project involved the selection of rural localities / small towns in each of the 6 counties where data will be collected in 2021. For this purpose, we performed a secondary analysis of the data from the SIPOCA 4 project (MLSJ / NIER, 2016-2018), mentioned above, validated, where possible, with official NIS data. By crossing the two categories of indicators, of underdevelopment, at local level, respectively, of the incidence of marginalized areas, we identified a list of indicators that characterize in various combinations, types of localities. The specific ways in which various combinations of indicators are made, at local level, generate typologies of under-development that will represent important landmarks in the selection of localities where data will be collected in the next stage of the project.

The preliminary comparative analysis of the socio-economic profile of the 3 categories of localities includes the indicators selected and presented in the table below.

Table 2. Development indicators

\begin{tabular}{|l|}
\hline The average population \\
\hline The average distance from the nearest city with over 30,000 inhabitants \\
\hline The average distance from the county town-center \\
\hline No. employees per 1,000 inhabitants \\
\hline No. persons left to work abroad / per 1000 inhabitants \\
\hline No. commuters per 1,000 inhabitants \\
\hline Weighted average poverty rate \\
\hline$\%$ of the self-employed population in agriculture in their own household and on their own land \\
\hline$\%$ of people benefiting from VMG \\
\hline$\%$ dropout after 8 th grade (students who do not enroll in high school) \\
\hline
\end{tabular}

In addition to the general characteristics that characterize the socioeconomic profile of each locality, such as geographical positioning, main sources of income, local and regional labor market, accessibility and quality of infrastructure (roads), access to public 
utilities, school infrastructure, the profile is configured by a series of characteristics that describe in specific ways the local context and enhance the process of local development, as well as the impact of this process on some categories of population.

Vulnerabilities and vulnerable people also exist in poor localities in poor areas, in underdeveloped localities in relatively developed areas, but also in localities with medium or high degree of development, either vulnerable in marginalized areas or marginal in non-marginalized areas.

The desk research stage integrated the analysis of the specialized literature related to the targeted topic and the secondary analysis of data collected in projects on consubstantial topics. The next stage was dedicated to strengthening the methodological approach and developing data collection tools. The desk research and secondary data analysis stage resulted in the selection of localities where data will be collected in the next phase of the project.

The proposed methodological approach was a mixed, mainly a qualitative one, the analysis of the data collected by filling in data sheets at ATU level, validated and completed with statistical data, representing the background on which the qualitative research was designed. Local data collection targeted the following target groups: relevant institutional representatives at local level; population in marginalized and nonmarginalized areas, respectively vulnerable people from marginalized areas (two subcategories: vulnerable Roma people; vulnerable non-Roma people).

Although we did not propose the statistical representativeness of these categories of localities, respectively, respondents from each locality, our approach aimed at respecting the desideratum of a theoretical representativeness, in the sense of comprehensiveness of the categories. Therefore, on the one hand, rural and urban localities were selected, localities from the plain area and from the mountain area of the county, located at greater or lesser distances from the county seat, with a significant share of the Roma population and without ethnic Roma. On the other hand, although the criterion for choosing respondents in this exploratory phase of data collection was mainly that of availability, we conducted interviews with relevant institutional representatives, at local level, individual interviews, but also focus groups with vulnerable people, Roma or nonRoma, as well as interviews with local entrepreneurs. 


\section{Synthesis of the results of the analysis of the data collected in Alba county - an exploratory case study. ${ }^{8}$}

In the first phase of the project, we set out to carry out an exploratory case study in Alba County for testing the research tools. In selecting the localities from Alba county, we considered the exploratory character of the proposed research approach. In this context, one of the selection criteria was the availability of respondents with the role of key informants. In addition to testing the tools and methodology, maintaining the flexible, less structured nature of the approach, increases the heuristic potential of this exploratory approach.

Alba, being a county with a relatively large share of mountain and sub-mountain areas where animal breeding remains one of the basic activities for a significant share of families, in this context, the analysis aimed at the complex relationship between type configuration and weight of the types of employment and local development.

One of the types of underdevelopment analyzed in this case is that of relatively economically developed localities but underdeveloped from the complex perspective of the definition of local development proposed in the project. The complex relationship between employment and social development is operationalized by the relationship between the type of employment and its efficiency, at the individual level, on the one hand, at the community level, on the other hand. When employment is effective, but a small share of the working age population is employed, the poverty rate is high, while that of in work poverty is low.

The ideal situation, in which both the poverty rate and the poverty rate at work are at a level significantly below the national average is conditioned by the existence of a large share of the employed working age population, and by employment efficiency. Simultaneous fulfillment of the two conditions is a prerequisite for social development, but social development also depends on the type of employment, not just its effectiveness. Only in certain contexts is individual employment efficiency transferred to the high level of local development.

The low degree of local development, reflected by the low stock of education, the low share of employees and the prevalence of agricultural activity, is also characteristic of some localities that are not poor and where the standard of living is average or above average, from the income perspective. The identification of communities with a similar social development profile, both in poor areas and in areas with a relatively high level of development, substantiates as a research hypothesis the existence of mechanisms of

\footnotetext{
${ }^{8}$ Synthesis of the results of the analysis of the data collected in Alba county is made by Mihnea Preotesi (author of the case study in Alba)
} 
community underdevelopment that follow a common structural logic that we find even in developed areas of the country.

In addition to other previous research experiences, very recent preliminary results of a research project on a complementary topic validate the hypothesis stated above and provide the premises for in-depth analysis of these mechanisms that maintain the spiral of social underdevelopment in "rich" rural communities.

One such example is that of some of the mountainous and sub-mountainous areas, where animal breeding has represented and still represents an activity that can bring income that ensures a decent living for farmers and their families, but which does not generate local development. Subsidizing agricultural activity "can produce, in certain local contexts, ambivalent and opposite effects, from the perspective of farmers, respectively, from the perspective of local development" (Preotesi, 2020).

In the context described above, we selected a small town, Abrud, located in a submontane area, respectively, a locality in the Apuseni Mountains, Albac commune. The third locality selected for this exploratory study is a locality from the plain area, with a pronounced agricultural character, Bucerdea Grânoasă commune.

While the first two localities are at great distances from the county center town, but also from any important city, Bucerdea Grânoasă is located at a relatively short distance from Alba Iulia $(30 \mathrm{~km}$.) And only $10 \mathrm{~km}$ from Blaj municipality.

The greater proximity to an important city, the higher access of the population to the public utility infrastructure, on the one hand, the relatively large share of the Roma population and the population living in marginalized areas, on the other hand, individualizes this locality among the three selected localities.

The data collected in the three localities from Alba County were collected from a predominantly qualitative perspective, being validated and supplemented with data collected from a quantitative perspective, through questionnaires addressed to ATU ${ }^{9}$ representatives, from the project database mentioned above (SIPOCA 4 ).

In each of the three localities in Alba County where we collected data, we identified specific elements that can generate positive or negative effects on local development.

Albac commune, due to the great distance from the county seat and any other city with over 30,000 inhabitants, low population and its spread in 16 villages, with some houses scattered on steep slopes difficult to access, large percentage of the population occupied in agriculture and the low share of employees, has premises of local under-development. The presence of a high school in the locality, the tourist potential, having an accentuated positive tendency of capitalization and development of associated services,

\footnotetext{
${ }^{9}$ Territorial administrative units
} 
on the one hand, the experience and resources generated by working abroad, the experience of accessing European funds for building and developing agritourism pensions, on the other hand, represent elements that can support a process of sustainable local development.

However, it depends on the way it takes advantage of the local resources, and on the concrete ways in which tourism can have a significant positive impact at the local level, through the effect of multiplication in the local economy. The diversification of the tourist services offer, and the professionalization of this activity will be able to increase the number of employees in the commune and to increase the efficiency of agricultural activities.

The balanced exploitation of local resources and the protection of the environment will be particularly important, today subject of an intensive exploitation of wood and other aggressions, such as intensive grazing. This phenomenon, less present here, in the conditions in which there are not very large farms, with thousands of sheep, is not serious both by its magnitude, but by the inefficient use of natural resources, materialized in the high degree of waste, as long as subsidies are seen as an end and not as a mean of increasing the economic efficiency of the activities.

The city of Abrud also has ambivalent characteristics from the perspective of local development. Although, compared to rural localities and small towns in Romania, both the share of employees in the employed population and the education stock are at a relatively high level, the differences compared to developed urban areas are significant. The long distance from the county town center, the large share in the economy of the sources of income of a poorly efficient agriculture, carried out in small and very small individual farms, mining restructuring, significant migration of young people to cities and lack of occupational alternatives, the quasi-inexistence of local social services are rather unfavorable premises for local development.

Bucerdea Grânoasă commune is a commune in a process of local development in the last 14 years since it became an independent commune. There are elements favorable to development, such as the proximity to Blaj and the distance to the county seat, the significant share of local employees, investments made by city hall in improving infrastructure, including school infrastructure, the relatively low rate of permanent internal and external migration and the significant rate of successful circular migration.

However, this development process is hampered by certain characteristics that define the socio-economic profile of the locality. The low stock of education produces negative inter-generational effects, mainly, but not exclusively, for the Roma population. The percentage of students who access the higher educational level, after finishing high school in the locality is still quite low. 
The local supply of jobs locally is very precarious. Even if the alternative of commuting to Blaj, Teius or Alba Iulia is a handy one, the lack of local investments and local employers are indicators and factors that hinder local development, the local budget is not fed with consistent amounts from such a source of income.

From the data and observations collected on the spot, it appears that the discrepancies between the Roma and the non-Roma population, despite the reduction of the gaps on certain dimensions, remain significant. Considering the high and growing share of the Roma population in the commune (20\%), local development cannot be achieved without implementing a strategy to accelerate the reduction of these gaps. The increase of the education stock and the reduction of the discrepancies between the Roma population and the non-Roma population of the locality represent the main challenges of the local development process.

\section{Conclusions}

Therefore, in each of the three localities in Alba County where we collected data, we identified specific elements that can generate positive or negative effects on local development. The way in which these elements of local context are combined in a specific historical evolution, potentiates their impact on the local development process.

One of the conclusions of this first phase of the project is the need to refine the approach in the next phase of data collection, analysis, and interpretation. The static perspective of the analysis of the current situation of the selected localities from the perspective of local development will be integrated with the dynamic perspective of the processes aimed at the socio-economic evolution of the locality.

Such processes, identified in the exploratory approach presented in the Interim Report of the project aim at phenomena of reagrarization of some urban localities, the change of migration patterns and the local impact of these changes, the concentration of agricultural properties, the impact of growth and changes in agricultural subsidy conditions.

On the other hand, among the aspects that may have an indirect impact on the evolution of local economy activities and sources of income, there are certain legislative changes or certain developments in the "de facto" application of laws, such as those that are referring to deforestation.

The results of the first exploratory phase of the project, will be operationalized and integrated in the consolidated version of the data collection tools, both the files through which data will be collected at the level of the selected ATUs and in the qualitative data collection tools. 
20 Typologies of underdevelopment and marginalization in rural localities and small towns in Romania

\section{References}

Emery M., Flora C. (2006). Spiraling up: mapping community transformation with community capitals framework, available at https://www.researchgate.net/publication/254909093_ SpiralingUp_Mapping_Community_Transformation_with_Community_Capitals_Framework

Franck A G, (1996). The underdevelopment of development, Sage Publications

Inkeles, A., \& Smith, D. H. (1974). Becoming modern: Individual change in six developing countries. Harvard University Press.

Preotesi M. Subdevelopment concept (conceptul de subdezvoltare) in Zamfir, C., Stănescu, S. (2007). Enciclopedia dezvoltării sociale, Polirom

Preotesi, M. (2013). Mecanisme şi factori ai sub-dezvoltării comunităților. O analiză în mediul rural românesc, Revista Sociologie Românească, nr.4/2013, p.75-89

Preotesi, M. (2018). Precarious employment-poverty-in work poverty in local contexts of social underdevelopment, in Chivu L., Ioan-Franc V., Georgescu G., Andrei Jv. (ed.). (2018) The Romanian Economy. A Century of Tranformation (1918-2018), Proceedings of ESPERA, Peter Lang., vol.2, p.1023-1031

Preotesi Mihnea, (2020) Analysis of the differentiated impact of the dynamics of individual well-being on the local development in the Romanian countryside. An analysis in the mountainous and submontane rural areas, in the volume Zamfir C., Stănescu I. (coord.) (2020) Romania 19892019: social policies and strategic options, manuscript

Rostow W W. (1959). The Stages of Economic Growth Author(s) The Economic History Review, New Series, Vol. 12, No. 1 (1959): 1-16, Available at https://www.ufjf.br/oliveira_junior/ files/2009/06/rostow.pdf

Sandu D. (1999a). Dezvoltare şi sărăcie în satele României, Revista Sociologie Românească, nr. 4/1999: $117 / 138$

Sandu D. (1999b). Spațiul social al tranziției, Iasi: Polirom.

Sandu D. (2001). Cum „ajungi” într-un sat sărac: drumul sociologic, Revista Sociologie românească, nr.1-4/2001: 153-171

Sandu D. (2011) Disparități sociale în dezvoltarea şi în politica regională din România, International Review of Social Research, vol.1, available at http://archive.sciendo.com/IRSR/irsr.2011.1. issue1/irsr-2011-0001/irsr-2011-0001.pdf

Tesliuc, Grigoras, Stănculescu (2016) Atlasul Zonelor Rurale Marginalizate şi al Dezvoltării Umane Locale din România, Banca Mondială, available at http://www.mmuncii.ro/j33/images/ Documente/Minister/F6_Atlas_Rural_RO_23Mar2016.pdf

Swinkels, R. et al. (2015). Atlasul Zonelor urbane marginalizate din România, available at https:// adrvest.ro/attach_files/Atlas_18Aprilie_RO_final.pdf 